Modigliano.-On a palæontological discovery made at Montegazzo in Fellina (province of Reggio-Emilia), by Prof. A. Ferreti.-On some recent communications made to the Paris Chemical Society, by the Editor.- On the filling of a barometer tube in vacuo, by Prof. Damiano Macaluso.

THE Archives des Sciences physiques et naturelles (September, Geneva) contain the following papers of note :-Review of the principal publications on physiological botany during 1878 , by M. Marc Micheli.-On xylic acid, its preparation and compounds derived from the same, by MM. E. Ador and Fr. Meier.-Note on the last report of the Council of the Royal Astronomical Society (London), by Prof. Gautier.-Analysis of some recent works relating to the topography and the constitution of the moon, by M. Rapin. - Account of the sixty-first meeting of the Swiss Naturalists' Association, on Aug. I2-14, 1878. The remaining contents of the number consist of mere extracts from papers published in other serials and relate all to chemistry.

La Natura (vol. iii., Nos. 16 and I7) contains the following papers of interest :-On the intensity of electric currents and of extra-currents in the telephone, by G. Farraris.-On the correction of mercury thermometers, by C. Ferrari.-Observations made during the earthquake of August 9 last, by A. Serpieri. -On two new meteorological works, by C. Ferrari.

\section{SOCIETIES AND ACADEMIES LONDON}

Mineralogical Society of Great Britain and Ireland, October 21.-Dr. M. Forster-Heddle, president, in the chair. The following papers were read:-On the mineralogy and geognosy of the Orkney Islands, by the president. -On a probably dimorphous form of tin, by Dr. C. O. Trechmann.On some Cornish tin-stones and tin-capels, by J. H. Collins, F.G.S.-Experiments on the elasticity of minerals, by John Milne.-On a peculiar pasty form of silica from Leadhills, Scotland, by Andrew French, F.C.S.

\section{PARIS}

Academy of Sciences, October 27.-M. Daubrée in the chair.-The following papers were read:-Notice on the life and scientific works of M. Dortet de Tessan, by Admiral Paris. -On the galvanic oxidation of gold, by M. Berthelot. This refers to Grotthuss's observation of the dissolving of gold-wire when used as positive pole in sulphuric acid traversed by a current. The attack is not due to formation of persulphuric acid, but solely to the influence of the current and contact of the electrode with the electrolysed liquid.--Decomposition of selenhydric acid by mercury, by $\mathrm{M}$. Berthelot. He observed such decomposition when the substances had been in contact with each other a few years. - Note on the development of railways in Brazil, by Gen. Morin. Two maps from the Emperor were shown. The total length of railway in operation in the provinces of Rio de Janeiro, St. Paul, and Minas Geräes, is 2,882 $\mathrm{km}$. ; in construction, $1,75 \mathrm{r} \mathrm{km}$. ; total, $4,633 \mathrm{~km}$. From $\mathbf{I}, 000 \mathrm{~km}$. to $\mathbf{I}, 200 \mathrm{~km}$. of the working lines have a broad gauge of $1.60 \mathrm{~m}$.; the rest, for local traffic, a gauge of $1 \mathrm{~m}$. The mountain chain near the sea in Rio de Janeiro presented great difficulties, but beyond, the railways lie in long and fertile valleys.-Critical reflections on experiments concerning buman beat, by M. Hirn.-On the gymnastics of M. Zander of Stockholm, by M. Norström. This is a system of mechanical and passive gymnastics, machinery worked by steam being used to move the limbs of the subject in various ways (the force being suitably proportioned). M. Larrey remarked on the complicated and expensive nature of the apparatus, and desired scientific data as to the effects obtained.-Result of researches made with a view to find the origin of estival reinvasions of phylloxera, by M. Faucon. The principal cause he considers to be carriage by the wind (inferred from the result of fixing a sheet of oiled white paper on a board at the top of a post facing the wind). Other causes are passage of the insect on the surface of the ground, and the presence of eggs.-On the appearance of mildew or false American oildium in the vineyards of Italy, by M. Pirotta. - Determination of longitudes, latitudes, and azimuths in Algeria, by M. Perrier. He shows that the probable error of each definitive result is about one-tenth of a second of an arc. Specific heats and points of fusion of different refractory metals, by $M$. Violle. The specific heat of iridium grows regularly with the temperature, and the formula gives $195^{\circ}$ (of the air-thermometer) as the point of fusion. The specific heat of gold hardly varies up to $600^{\circ}$, then gradually increases towards the point of fusion, $1035^{\circ}$. Other points of fusion: silver, $954^{\circ}$; copper, ro32 $2^{\circ}$, palladium, $1500^{\circ}$, platinum, $1775^{\circ}$.-Chloride of lime battery, by M. Niaudet. The positive electrode is a zinc plate in a solution of chloride of sodium. The negative, one of carbon surrounded by fragments of carbon and chloride of lime in a porous vessel. All the combinations produced are soluble, and the battery remains an indefinite time at rest without being used up. The electromotive force at first is over $\mathbf{r}^{\circ} 6$ volt. - On the combinations of phosphuretted hydrogen with hydracids, and on their heat of formation, by M. Ogier.-On erbine, by $M$. Clève. He recognises $M$. Soret's priority, and the identity of the substances he himself called holmium, with M. Soret's X.Complementary note on commercial trimethylamine, by MM. Duvillier and Bursine.-On ordinary cellulose, by M. Franchimont. This refers partly to dehydration of cellulose with sulphuric acid (chloride of zinc did not decompose cellulose).On glucose, by M. Franchimont.-On the transmissibility of human rabies to the rabbit, by M. Raymond. Two rabbits were inoculated with blood and saliva (respectively) from a hydrophobic person. That inoculated with saliva showed signs of rabies four days after, and soon died. Pieces of its salivary glands (got thirty-six hours after death) were introduced into two other rabbits, who also died (paralysed), but without passins through a violent stage.-Researches on Daltonism, by MM. Macé and Nicati. Theyaimed at comparative measures of the quantities of light perceived in different parts of the spectrum by the Daltonian and the normal eye. Curves were got corresponding to the three varieties of Daltonian eye. The descent of the curve in the green the authors think they have been the first to prove certainly. No simple relation between visual activity and intensity of light was ascertained. - On the origin of the toxical properties of the Indians' curare, by M. Du Lacerda. None of the vegetable or animal juices often added by the Indians to the product of Strychnos have the effects of curare, and Strychnos castelnter, also, $S$. triplinervia, are found to give curaric effects fully. $-\mathrm{Ex}$. perimental researches on human heat during rest in bed, by M. Bonnat. In all seasons the minimum of the body-temperature (observed in the rectum) is between midnight and 3 A.M. At Nice, in winter, the minimum is rarely under $36^{\circ} 3$; in summer, $36^{\circ} 4$ or $36^{\circ} 5$. From 3 A.M. the temperature rises till 9 A.M. (becoming, e.g., $36^{\circ} .9$ in winter). The maximum is between 2 P.M. and 4 P.M., and from 9 P.M. the temperature slowly falls to the minimum. From 9 A.M. to 9 P.M. in winter the varia tions do not exceed three-tenths or four-tenths of a degree C. in summer they may reach six-tenths.

\section{CONTENTS}

Page

ON Certain Errors Rhspecting the Structure of the Hrar ATtributed to Aristotle. By Prof. T. H. HuXLey, F.R.S. (With

ON THE NeCESSiTy For A New Defarturu in SPECTRUM ANAlysis. By J. Norman LockYer, F. R.S. ' OUR BOOK SHEIF:-

Mrs. Fenwick Miller's "Atlas of Anatomy, or Pictures of the Human Body

Higgs's "Electric Transmission of Power."- $\dot{W}, \dot{F}, \dot{B} .: \dot{*}:$

LETTERS TO THE EDITOR:-

Sun-Spots in Earnest.-Prof. A. Winnecke . . . . . . . . ro

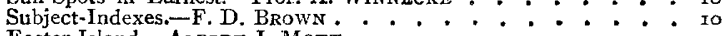

Easter Island.-ALBf RT J. MотT • . . . . . . . . . . II

Animals and the Musical Scale-Wilisim Pole: : : : : II

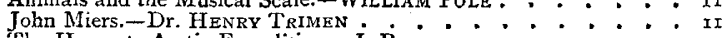

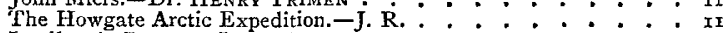

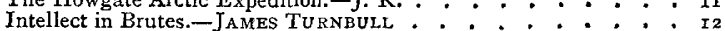

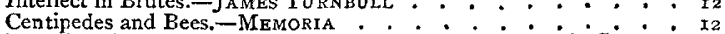

Bone-Sucking-A Habit of Cattle.-W. Frazer ; Jorin LEConTE. I2

Bone-Sucking-A Habit of Cattle.-W. FRAZER; JOHN LECONTE. I2

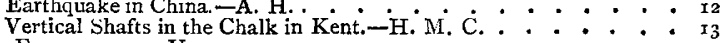

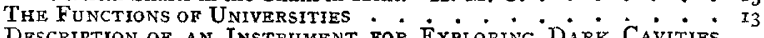

DESCRIPTION OF AN INSTRUMENT FOR EXPLORING DARK CAVITIES

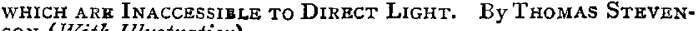
SON (With Illustration) . . • . • . . . . . • . • • • . I4

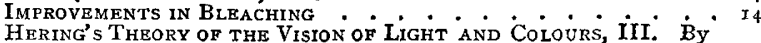
Hering's TheORY OF THE Vision OF Light and Colours, III. By

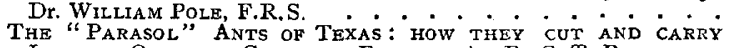
Leaves; Origin of Castes by Evolution. By G. T. BetTany. I Notes. OUR Astronomicai ColUma :-

Minor Planets in 1880

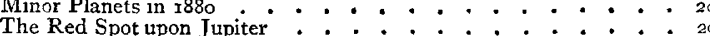

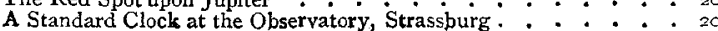
Physical Notes

Geogkayhical Noties

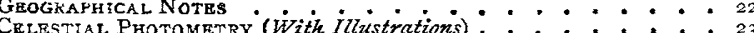
UNIVERSITY AND EDUCATTONAL INTBLLIGENCB SCIENTIFIC SERTaLs SOCIRTIES SRRIALS 